\title{
A reconfiguração do trabalho docente na educação superior ${ }^{1}$
}

\section{Reconfiguration of faculty work in Higher Education}

\author{
Olgaíses Maués ${ }^{2}$
}

\begin{abstract}
RESUMO
A análise do trabalho docente na educação superior vem ganhando destaque na literatura em função das nuances que tem acompanhado essa atividade. O presente trabalho faz uma análise das transformações pelas quais a educação superior vem passando como consequência da Reforma do Estado e dos reflexos mais visíveis dessas mudanças no trabalho do professor. Também são analisadas algumas das recomendações emanadas de conferências regionais, nacionais e internacionais ocorridas nos últimos anos sobre a educação superior, visando estabelecer algumas relações entre elas e o papel que a Universidade vem assumindo e com as novas demandas postas para o docente que nela atua.

Palavras-chave: trabalho docente; educação superior; reformas educacionais.
\end{abstract}

\begin{abstract}
The analysis of faculty work in higher education has been extensively mentioned in literature due to the specificities of its activities. The present work analyzes the changes higher education has been undergoing as a consequence of the Brazilian State Reform and the clear influences of such changes on professors' work. This work also focuses on analyzing the recommendations that have been made by regional, national, and international higher education conferences in the last few years aiming at establishing relationships of those recommendations with the role the university has assumed more recently and with the new demands on its faculty members. Keywords: faculty work; higher education; educational reforms.
\end{abstract}




\section{Introdução}

O trabalho docente vem se modificando à medida que a educação superior está passando por transformações significativas, sobretudo a partir do final dos anos 1990, recebendo nas últimas décadas uma atenção especial, em função do papel que lhe vem sendo atribuído, enquanto propulsora do desenvolvimento econômico. O estudo das atividades que esse trabalhador passa a desempenhar tem despertado interesse de diferentes pesquisadores, com matizes teórico-políticas diferenciadas. Quando se trata do trabalho do professor da educação superior, a questão ganha contornos específicos, tendo em vista as funções que esse nível de ensino representa no crescimento de um país, na produção do conhecimento, da ciência e da tecnologia, elementos fundamentais para o desenvolvimento social e econômico.

Analisar o Trabalho Docente na Educação Superior é um desafio importante, à medida que as reformas em curso têm alterado as finalidades da educação e esse fato tem repercussões nas atividades desenvolvidas por esse profissional. A Reforma do Estado brasileiro iniciada na metade dos anos 1990 é um marco referencial para que se entenda o papel que a educação superior passou a desempenhar no seio das estratégias governamentais, levando a uma permanente e constante reforma desse nível de ensino, fazendo com que esta esteja presente nas Agendas dos governos de forma marcante, a partir da última década do século passado e dos primeiros anos do terceiro milênio. $\mathrm{O}$ destaque dado a esse nível de ensino não é ao acaso. Ele faz parte de um arranjo internacional que indica a importância da educação para o desenvolvimento dos países.

As recomendações emanadas de organismos internacionais (BM, 1994, OCDE, 2008) têm apontado para a adaptação dos sistemas educacionais, sobretudo os de nível superior, às exigências do mercado, colocando as universidades a serviço das empresas. Nessa lógica de vinculação da educação ao mercado, o papel e as funções das universidades passam a ser questionados e surgem novas propostas que orientam as reformas desse nível de ensino. Nesse contexto, o trabalho docente também é alvo das mudanças e esse profissional passa por uma metamorfose que o distancia das tradicionais funções pelas quais era responsável.

O que se pretende analisar neste estudo é a relação existente entre essas mudanças (reforma do Estado e da Educação Superior) e o trabalho do docente que atua no ensino superior, buscando estabelecer os nexos e procurando identificar quais os caminhos que o trabalhador da educação vem sendo impelido a trilhar para se ajustar a esse outro ensino. 
Para tanto, procuraremos situar o papel da reforma do Estado na Educação Superior, assim como situar algumas das tendências oriundas das recomendações da Conferência Mundial de Educação (CMES, 2009), da Conferência Regional da Educação Superior da América Latina e Caribe (CRES, 2008), do Fórum Nacional da Educação Superior (FNES, 2009) e como elas estão incidindo sobre as reformas que estão ocorrendo nesse nível de ensino.

As posições de alguns intelectuais e do Sindicato da categoria (ANDES-SN) a respeito das reformas que vêm se processando na educação superior serão também apresentadas e analisadas, possibilitando que se tenha um panorama amplo do que vem ocorrendo com esse nível de ensino no tocante às políticas e às influências destas no trabalho do docente.

O trabalho é parte de uma pesquisa em desenvolvimento, financiada pelo $\mathrm{CNPq}$, que busca identificar as mudanças na cultura acadêmica, resultantes da reestruturação em curso na Universidade. A pesquisa tem como objetivo analisar as mudanças no trabalho docente e os possíveis nexos entre este e a nova regulação das políticas da educação.

\section{A nova face da educação superior}

No contexto de crise dos anos 1980 do estado capitalista brasileiro, o governo começou a desenhar uma nova relação entre política e economia como recurso preferencial para a saída dessa situação. Na lógica adotada, o nível político passou a estar subordinado aos interesses econômicos, o que deu o contorno à reforma do Estado. Essa Reforma tem uma importância fundamental para se compreender as mudanças sofridas na educação superior, à medida que um dos pontos cruciais apontados pelos seus ideólogos foi a descentralização de algumas ações e a publicização de outras, a título de que o Estado estava "inchado". As críticas ao estado burocrático e o aceno para a constituição de uma forma descentralizada de gestão se constituíram nos pontos fulcrais desse processo. A Reforma do Estado, que vinha na esteira de uma das crises do capitalismo, propunha um Estado mínimo no tocante às intervenções no mercado e máximo nas relações comerciais no plano internacional. A forma de operacionalizar esse novo modelo de Estado exigia a criação de dois grandes núcleos, que foram denominados de burocráticos, responsáveis pelas funções exclusivas do Estado e o núcleo de serviços, responsável pelas funções não exclusivas a serem desempenhas pelo Estado. É esse modelo que vai servir de parâmetro para a reforma da educação superior, isso porque os centros de pesquisa científica e 
tecnológica foram transformados em atividades não exclusivas do Estado, na compreensão de que essas são atividades competitivas e que por isso podem e devem se constituir em quase-mercados (PEREIRA, 1998).

O lugar da educação superior ficou bem definido nesse contexto do Estado reestruturado. À medida que a educação superior foi considerada como um serviço não exclusivo do Estado, podendo ser ofertada por organizações sociais, também denominadas públicas não estatais, criou a necessidade da existência de mecanismos de regulação e avaliação. Ao poder público ficou a responsabilidade da definição dos objetivos e a avaliação dos resultados, observando-se os parâmetros de eficiência, eficácia e qualidade estabelecidos, em geral, pelas exigências do mercado. O Estado passa a ser chamado de regulador e avaliador em função das novas funções que assume. A compreensão do papel da regulação é fundamental nesse novo desenho. Para Aglietta (1976) o modo de regulação "é o conjunto de mecanismos e de instituições que permitem o funcionamento da acumulação capitalista relativamente estável durante alguns períodos". Com isso, fica definido que ao Estado compete ter sobre essas atividades, consideradas não exclusivas, apenas a função de regulação e controle. Além dos aspectos mencionados, a reforma do Estado que trouxe o ajuste fiscal, com o corte dos gastos públicos e o enxugamento da "máquina administrativa", tem levado a categoria docente a uma constante precarização das suas condições de trabalho em função do arrocho salarial, dos aumentos concedidos apenas nas gratificações as quais são incorporadas apenas parcialmente quando ocorre a aposentadoria.

A Educação Superior vem sofrendo uma série de mudanças em âmbito mundial, falando-se mesmo em reestruturação desse nível de ensino. As alterações que são apontadas representam modificações no sentido das finalidades, dos objetivos da educação, o que representa outra arquitetura acadêmica, pedagógica e social que possa vir a dar conformação àquilo que é posto como sendo, na contemporaneidade, a "missão" da Educação Superior.

As funções da Educação Superior assumidas no momento do surgimento da Universidade Moderna, século XIX (Humboldt), que aliavam o ensino à produção do conhecimento, parecem vir sofrendo um duro questionamento. Pedro Goergen, ao apresentar uma obra de Dias Sobrinho (2005), indica a existência de uma crise nessa instituição, que abrange o princípio de universidade, o contexto na qual esta está inserida, representada por uma sociedade globalizada, informatizada e também uma crise textual, significando os desafios de formar profissionais e pesquisadores éticos.

Mesmo que não haja uma concordância plena com o entendimento sobre a natureza da crise, há certo consenso de que a Educação Superior passa por um processo de transformação que se reflete diretamente no papel que as Universidades vêm a desempenhar na sociedade. 
Para falar nessas mudanças na educação superior nos centraremos mais especificamente nas Universidades, nas funções desempenhadas, no papel que dela é demandado pela sociedade dita do conhecimento, nas relações que são mantidas ou rompidas com o Estado, nas reformas implementadas e nas justificativas para tais. Apesar dessa situação estar generalizada tanto nos países centrais, propulsores dessas mudanças, quanto nos demais, com destaque para a América Latina, nos ateremos mais diretamente ao Brasil sem, contudo, deixarmos de fazer ilações com outros contextos, desde que pertinentes.

\section{Os grandes marcos internacionais}

Com base nas decisões tomadas na Conferência Regional de Educação Superior na América Latina e Caribe (CRES, 2008) e no Fórum Nacional de Educação Superior (2009) e a partir dos resultados da 2a . Conferência Mundial de Educação, algumas questões estão postas relativas à identidade da Universidade e ao consequente trabalho do professor.

A Conferência Regional de Educação Superior na América Latina e Caribe, realizada em 2008, como etapa preparatória à Conferência Mundial de Educação Superior de 2009, coloca a educação superior como um direito humano e um bem público social, devendo os Estados garantirem esse direito. A partir da Declaração foi elaborado um Plano de Ação da Conferência Regional da Educação Superior (CRES), cujas diretrizes, em número de cinco, especificam: (1) a necessidade de expansão da educação superior, devendo, até 2015, os países da região terem atingido $40 \%$ de atendimento aos jovens, sem especificar a faixa etária. Uma política forte de inclusão deverá ser um dos instrumentos utilizados para tal. A Avaliação e a Qualidade (2) também estão presentes no Plano, devendo os sistemas de avaliação e acreditação incorporarem indicadores de cooperação solidária em nível nacional e internacional, utilizando os resultados desses processos para elaboração de políticas.

A terceira diretriz emanada da Conferência Regional (Inovação Educacional) e do Plano da CRES faz referência explícita aos professores, ao recomendar que estes devem ser motivados com planos de carreira e salários e que devem ser propiciadas condições necessárias ao exercício da função profissional. O estabelecimento de uma Agenda Regional de Ciência e Tecnologia está presente na diretriz de número quatro e finalmente a integração regional e a internacionalização fecham o elenco de recomendações. 
O Brasil, por meio do Conselho Nacional de Educação, elaborou um documento de referência para o Fórum Nacional de Educação Superior, baseado na Declaração e no Plano de Ações da CRES. Este documento se centrou em três eixos: 1 - democratização do acesso e flexibilização de modelos de formação; 2 - elevação da qualidade e avaliação; 3 - compromisso social e inovação. Esses pontos serviram de base para a realização do Fórum Nacional da Educação Superior em maio de 2009. O documento síntese final desse evento foi organizado a partir das mesas 1. Democratização do Acesso e Flexibilização de Modelos de Formação; 2. Elevação da Qualidade e Avaliação; 3. Compromisso Social e Inovação. Algumas das convergências explicitadas no Fórum reiteram decisões anteriores, tais como aquela que coloca a educação como direito social e universal, como bem público; o destaque à excelência acadêmica (ou qualidade) e pertinência como conceitos interdependentes, esclarecendo que não há excelência acadêmica sem que esta seja acessível à sociedade; assim como não há pertinência social sem difusão da excelência. Em outras palavras, não podem os países terem universidades de estatura acadêmica em meio à desigualdade social, nem fugir do subdesenvolvimento sem um investimento contínuo em matéria de conhecimento e promoção da qualidade.

O ANDES-SN (Sindicato dos docentes da educação superior), ao se manifestar sobre o Fórum Nacional, explicita a posição historicamente assumida pela entidade em relação ao assunto, enfatizando o entendimento de que a educação superior é parte do direito subjetivo do cidadão, cabendo ao Estado o desenvolvimento de políticas públicas que garantam a sua efetivação. Outro aspecto destacado pelo Sindicato é aquele relativo à importância da indissociabilidade entre ensino, pesquisa e extensão, devendo este ser o balizador da ação docente e institucional.

Além desses compromissos outros foram reiterados na $2^{\text {a }}$ Conferência Mundial de Educação Superior ocorrida em julho de 2009, em Paris, promovida pela UNESCO. A própria temática já era bastante sugestiva tratando das "novas dinâmicas e pesquisa acadêmica", enfatizando a educação como um bem público, sendo, pois responsabilidade de todos os protagonistas do setor, em especial dos governos de cada país. O documento final destaca o papel primordial que o ensino superior desempenha para o estabelecimento da sociedade do conhecimento.

A partir desses conclaves regional, nacional e mundial estão reafirmados os marcos regulatórios da educação superior, devendo os países signatários assumir, por meio de políticas e reformas, as decisões acordadas. 


\section{O Brasil no cenário das mudanças}

O Brasil já vem fazendo reformas nesse nível de ensino faz algum tempo, por meio de medidas pontuais, muitas vezes aparentemente desconectadas umas das outras, mas que no fundo se constituem numa reformulação a retalhos. De maneira mais sistematizada, desde 2006 foi encaminhado pelo Executivo ao Congresso Nacional um Projeto de Lei (PL) que recebeu o número 7.200 e que passados três anos ainda não foi aprovado. Ao chegar à Câmara dos Deputados o PL recebeu 368 emendas apresentadas por parlamentares e foi apensado ao $\mathrm{PL} \mathrm{n}^{\mathrm{o}} 4.212 / 04$, que foi encaminhado primeiro à Casa e vai ser apreciado junto com outro PL de $\mathrm{n}^{\circ}$. 4.221/04 e mais onze outros projetos em tramitação ${ }^{3}$.

O ANDES-SN fez uma análise do PL 7.200 e aponta alguns aspectos, no documento, que também contemplam as orientações do Banco Mundial, tais como a diferenciação das instituições de educação superior, o que, segundo a análise do Sindicato, quebraria a possibilidade de uma qualidade unitária, princípio defendido pelo Movimento Docente. Além desse aspecto outros são enunciados na análise do Projeto de Lei: a visão da educação como um bem público, e não como um direito social, conforme expresso na Constituição Federal de 1998 ( $\operatorname{artigo} 6^{\circ}$.), deixando de ser um direito de todos e dever do Estado. A Educação a Distância tem um destaque muito grande nesse projeto do governo, ocupando um espaço significativo em relação à graduação, às licenciaturas e à formação inicial.

Mas o fato de não se ter ainda uma reforma desse nível de ensino traduzida numa legislação única, como ocorreu em 1968 com a lei 5.540, não significa que na realidade o executivo esteja aguardando a posição do legislativo em relação aos projetos de lei. O governo tem, por meio de Medidas Provisórias ou Decretos-lei, realizado na prática a reforma da educação superior. A lei do SINAES (Sistema Nacional de Avaliação da Educação Superior); a lei de Inovação Tecnológica; a lei da Parceria Público-Privada; o chamado decreto-ponte (5.773 de 2006) que estabelece uma conexão direta entre avaliação e regulação; o decreto que instituiu o REUNI (Programa de Apoio ao Plano de Reestruturação e Expansão das Universidades Federais); as Portarias Ministeriais que criaram o Banco de Professor Equivalente; o decreto que institui os Institutos Federais de Educação, Ciência e Tecnologia - IFET são alguns dos exemplos que confirmam a tese de que a reforma está sendo feita.

3 Os projetos de lei que tramitam no legislativo, numa profusão que denota muitos interesses, trazem a marca da privatização, da flexibilização relativa tanto à organização administrativa quanto a exigências de titulação dos professores, revelando uma face que indica a abertura da educação superior ao capital estrangeiro. 
Esse aparato legal tem alterado a "missão" da Universidade e tem incidido diretamente sobre o docente, em alguns casos intensificando, noutros precarizando o trabalho desse profissional. Os resultados dessas mudanças no papel do professor vêm sendo objeto de estudo por diferentes áreas incluindo a saúde.

\section{Algumas resistências explicitadas}

Mas as mudanças produzidas pela regulação de políticas implementadas pelos governos não obtém aprovação unânime. Muitos intelectuais e alguns movimentos sociais têm se manifestado contrários a essas políticas.

Marcela Mollis (2003), analisando a situação da Argentina, fala, a respeito das Universidades, em "identidades alteradas", dizendo que estas instituições perderam a razão de ser:

Ao quebrar-se o contrato social com o Estado e ser "jogada" às forças do "todopoderoso mercado", as universidades públicas e privadas da América Latina começaram a praticar a "mercadotecnia"4' como uma alternativa para recuperar seu debilitado financiamento e buscar uma nova identidade. [...] O sentido da grande transformação universitária na América Latina nos anos 90 foi a mudança da identidade pública universitária - necessária durante o império do Estado Benfeitor - para uma identidade em trânsito no contexto global do Estado empresarial (p. 9, 10).

A autora citada chama a atenção para o fato de que as reformas ocorridas em alguns países da América Latina, dentre eles o Brasil, dão importância a accountability, à prestação de contas, aos resultados. As metas são estabelecidas pelos governantes e após, por meio de instrumentos avaliativos externos, são verificados os resultados.

Essa noção de accountability, juntamente com a de responsiveness evidencia a linguagem do mercado e significa que o financiamento da educação superior está condicionado aos indicadores de rendimento, tais como o índice de matrícula, o custo por aluno, as taxas de conclusão de curso, dentre outros.

4 Mercadotecnia é o conjunto de técnicas, estratégias e aplicações para a consecução dos objetivos do Mercado, é o termo em castelhano para o inglês marketing. 
Nesse modelo de accountability não se dá destaque ao processo. Barroso (2006) explicita esses procedimentos como uma regulação, esclarecendo que esta é mais flexível na definição dos processos e rígida na avaliação da eficiência e eficácia dos resultados, ao contrário da regulamentação que é rígida no controle do processo.

$\mathrm{O}$ peso dos governos neoliberais na região levou à mudança de identidade das Universidades, que passam de instituições dos saberes para uma identidade que se aproxima do supermercado, onde o estudante é tratado como consumidor ou cliente, os saberes como uma mercadoria e o professor se converteu em um "assalariado enseñante". Essa mudança de identidade, à qual Mollis se refere, estaria relacionada ao vínculo da Universidade com o mercado, aproximando-se do que Le Grand (1996) denomina de quase-mercado, significando a introdução de mecanismos do mercado na educação pública.

Naidorf (2005), outra pesquisadora argentina, fala em privatização do conhecimento público e com isso se refere à emergência de uma "nova" cultura acadêmica. Para a autora essa privatização significa que o conhecimento produzido na universidade pública, com financiamento privado, apresenta cláusulas de confidencialidade que impedem, ou pelo menos limitam o livre fluxo dos resultados. Além desse aspecto, a autora, chama a atenção para o fato de que isso também vai ser determinante na seleção dos temas de pesquisa, tendo uma repercussão sobre o trabalho docente, pois este profissional será remunerado segundo os critérios empresariais.

A posição de Naidorf se aproxima daquela indicada por Schugurensky (2003) em relação à heteronomia da Universidade, e da dificuldade de se compatibilizar os objetivos do setor público e o ethos acadêmico com os interesses privados. Essa relação direta entre a Universidade e a Empresa traduzida pela produção do conhecimento sob demanda, comprometendo os professores na realização de pesquisas que são encomendadas por quem financia, apresentando restrições de divulgação e utilização, tem levado a uma mudança da cultura acadêmica.

Naidorf (2005) conceitua a cultura acadêmica como sendo a maneira de ser e fazer dos cientistas da universidade pública. De forma mais esclarecedora a autora explica como essa cultura se manifesta e o que pode significar para a concepção de universidade e para o trabalho docente.

A cultura acadêmica da Universidade está configurada pelos discursos, representações, motivações, normas éticas, concepções, visões e práticas institucionais dos atores universitários acerca dos objetivos das tarefas da docência, investigação, extensão e transferência, que condicionam substancialmente as maneiras de realizar as mesmas. 
A mudança na cultura acadêmica se manifesta na Universidade de variadas maneiras que vão desde a naturalização da relação conhecimento-mercado, para a qual não haveria alternativas e sem a qual a instituição não teria condições de sobrevivência, passando pela situação que Naidorf chama de voluntarista, ou seja, de que os docentes podem ou não aderir a essa concepção mercantilista e, finalmente, uma última forma de manifestação que é a denominada dialética, representada pela constatação do peso do mercado e admitindo que hoje a Universidade é um espaço em disputa. Nessa última posição de disputa e negociação seria necessário que os atores levassem em consideração as questões éticas e não sucumbissem simplesmente às pressões externas, traduzidas, muitas vezes, por remunerações extras, compras de equipamentos, viagens ao exterior e outros atrativos financeiros, oferecidos àqueles que aderem a essa nova cultura.

Em uma pesquisa ${ }^{5}$ realizada com professores doutores das diferentes áreas do conhecimento em uma universidade federal, tomando como referência professores que ingressaram na instituição antes da Reforma do Estado e aqueles que ingressaram após esse marco, Maués (2009) pode constatar que de fato a cultura acadêmica vem se modificando. $\mathrm{O}$ que se pode analisar das falas dos sujeitos docentes do primeiro grupo (ingressantes antes da Reforma) é de que "a vida era bem mais fácil, eu vinha dar minhas aulas, tinha o meu laboratório e ninguém vinha com essa história de nota, conceito, avaliação da CAPES. Nós sabíamos o que fazer, não precisava cobrar". A natureza do trabalho do docente, sobretudo na pós-graduação, passa a ser o grande balizador das ações que vão ocorrer na universidade. A partir dos anos 2000, quando essa instituição de ensino passa a fazer concurso exigindo como critério de inscrição o título de doutor (em casos excepcionais de mestre) há uma sensível diferença no corpo docente que então passa a se constituir. Esse fato pode ser percebido nessa fala:

[...] a ajuda externa, seja via agências de fomento, seja via empresas privadas é fundamental para meu desempenho aqui dentro. Tenho projetos financiados por uma empresa e estou fazendo uma pesquisa sob encomenda. Acho melhor, pois tenho recursos suficientes, não dependo do governo, e sei que os resultados da minha investigação serão plenamente utilizados.

5 A pesquisa em fase de conclusão, financiada pelo CNPq foi realizada na UFPA, envolvendo 8 professores doutores vinculados a Programas de Pós-Graduação. Os professores foram divididos em 2 grupos a partir do critério de vinculação aos Programas e área de conhecimento. 
Na mesma lógica da relação da Universidade com o mercado, vinculando-a à produção do conhecimento, à definição das pesquisas, à abertura de cursos é que alguns autores instituíram a expressão "capitalismo acadêmico" para essa configuração da educação superior na contemporaneidade.

Sheila Slaughter y Larry Leslie, em um livro de 1997, classificam como capitalismo acadêmico as relações que a academia tem com o mercado, desenvolvendo a pesquisa a partir dos interesses dos financiadores, e ao fato de o Estado diminuir os recursos para as Universidades, levando as atividades extensionistas a se tornarem captadoras de recursos externos. Para essas autoras as Universidades hoje estariam subordinadas ao mercado, perdendo a sua autonomia e se integram a redes de produção de conhecimentos, cujas decisões ocorrem a partir de interesses econômicos.

As posições apresentadas pelas autoras citadas vêm ao encontro daquelas já manifestadas e expostas neste texto de autores como Schugurensky, Naidorf, dentre outros. Ou seja, aquilo que se pode denominar de "privatização branca" das Universidades. A identidade dessa instituição está se modificando, as finalidades (missões) estão sendo definidas por agentes externos, a cultura interna está próxima àquela das empresas privadas, cujos indicadores são a eficiência, a eficácia, os resultados mensuráveis e a premiação vinculada aos resultados.

Dias Sobrinho (2005) alerta para o fato do efeito da globalização nas universidades e chama a atenção para a complexidade desse processo e as contradições que o mesmo suscita:

[...] Para o império do capital, a universidade adquire enorme importância, pois na visão economicista, tudo se transforma em capital: capital humano, capital intelectual, capital político etc. Na linguagem banco-mundialista, há uma grande tendência atualmente de se construir um "mercado mundial de capital humano de alto nível". (p. 123)

A globalização trouxe a internacionalização da educação. Leher (2006) dá destaque ao fato da atuação dos países centrais, por meio de seus intelectuais, de tornarem a mercantilização da educação um fato imprescindível e necessário. $\mathrm{O}$ autor destaca que este nível de ensino é o mais atraente para o capital internacional, o que fez com que os Estados Unidos divulgassem a ideia de que a universidade fundada no modelo humboldtiano não se coaduna com a realidade da América Latina, compactuando com o Banco Mundial (1994) a ideia da diferenciação das instituições. 


\section{O trabalho docente na Universidade}

Face à "nova" configuração da Universidade, o trabalho dos profissionais que nela atuam, com destaque para os professores, vem sofrendo mudanças substanciais, a fim de se adequar a essa instituição heterônoma, cuja identidade foi "alterada", que vem criando uma nova cultura acadêmica, que tem praticado um capitalismo acadêmico e se mercantilizando grandemente.

O trabalho do professor não pode ser analisado desvinculado desse contexto, até porque essas são as condições objetivas que esse profissional tem para atuar nesse espaço acadêmico. A nova regulação que inclui formas de financiamento, de gestão e de avaliação dessa instituição tem repercutido no trabalho docente.

A flexibilização, a precarização, a intensificação, o sofrimento, o adoecimento são expressões hoje que permeiam a vida do trabalhador docente. A reestruturação produtiva que se coloca mais fortemente a partir da crise dos 1970, impulsionada pela chamada revolução tecnológica, trouxe uma mudança estrutural na configuração do trabalho e nas relações que passaram a se estabelecer com o empregador. O setor da educação não ficou imune a esse processo caracterizado como o esgotamento do modelo taylorista-fordista-keynesiano.

As mudanças no trabalho incidiram diretamente sobre os docentes e estão imbricadas com a reforma da educação superior que vem acontecendo, baseada na reforma do Estado, na medida em que imputa ao trabalho docente o modelo de "gestão empresarial", numa lógica capitalista e mercadológica hoje dominante na maioria das Instituições Federais de Educação Superior (IFES).

O próprio ordenamento jurídico existente corrobora para que a educação superior e o trabalho dos docentes estejam subordinados às exigências do capital.

O estado neoliberal "enxugou" a máquina administrativa e com a ênfase dada à gestão, à descentralização e à avaliação passou a exigir do trabalhador docente outro perfil, aquele que deveria se coadunar também com as mudanças que a própria instituição Universidade vinha sofrendo.

A precarização do trabalho na Universidade vem aumentando. Os contratos temporários, o número significativo de substitutos tem contribuído para a intensificação do trabalho docente, exigindo desse a mais valia absoluta e relativa, acirrando a competitividade e estimulando o aparecimento de ilhas de excelência.

Mas a precarização vai além da flexibilização trabalhista. Bosi (2007, p.1505) considera "[...] como precarização do trabalho docente o aumento na rotina das atividades de ensino, pesquisa e extensão que compõe propriamente o fazer acadêmico". E nas Universidades são essas atividades, constitutivas 
e inerentes à instituição, que de fato servem de referência para que se possa analisar o processo de trabalho dos profissionais que ali atuam.

Os indicadores de desempenho baseados no mercado têm servido de parâmetros para premiação ou punição desse trabalhador que se vê acossado pelas demandas postas, que numa espécie de auto-aprisionamento tem se imolado no altar das agências de fomento, buscando financiamento, com o qual virá também o status, a respeitabilidade acadêmica e a premiação.

Na lógica das mudanças, na concepção e papel da Universidade, exposta na primeira parte do texto, o professor precisa ser um empreendedor (lei de Inovação Tecnológica), trazendo dinheiro para desenvolver não somente suas pesquisas, mas para também "manter" os departamentos, as pró-reitorias, a Universidade.

Mas essa intensificação significa a submissão às exigências dos editais que via de regra são voltados para atender aos interesses mais racionais e que tenham uma resposta econômica (capitalismo acadêmico).

Na lógica do empreendedorismo é preciso se submeter a avaliações como a do SINAES e à avaliação promovida pela CAPES, enquanto agência reguladora das políticas de formação docente. Os professores vinculados aos programas de pós-graduação precisam ser produtivos para neles ingressarem e se manterem, sem sofrer o constrangimento de serem "desligados" por falta de produção.

A mudança da cultura acadêmica (NAIDORF, 2005) tem instituído a naturalização desse produtivismo na Universidade. Há mesmo uma "servidão voluntária" à medida que os professores autointensificam o trabalho para que, em um processo de avaliação que é comparativo, possam obter mais "pontos" do que o colega e, portanto, maior possibilidade de conseguir o financiamento pleiteado seja para um projeto, para apresentação de trabalho no exterior, ou realizar um pós-doutoramento, para obter uma bolsa de produtividade, tornando-se assim um professor diferenciado.

Contudo, apesar de muitos professores constatarem a exploração à qual estão submetidos, esse fato ficou naturalizado, nessa nova cultura, sendo que alguns até justificam, explicando: "se não trabalhar nos finais de semana, não dou conta dos meus artigos. No início achava ruim, estranho, hoje estou de bem comigo e decidi que tenho um periodo no sábado ou no domingo que dedico ao lazer [...] para mim é suficiente, o resto fico no computador e confesso que não me sinto sacrificado com isso, pois sei que o resultado será prazeroso." (MAUÉS, 2009).

$\mathrm{Na}$ lógica mercantilista que rege as Universidades, os professores passam a ser "reféns da produtividade" (BIANCHETTI, 2007). A quantidade de "produtos", textos, livros, orientações concluídas, participação em eventos com apresentação de trabalho, organização de eventos, emissão de pareceres para as agências de fomento e Revistas, participação em Banca de Defesa e de 
Concurso, as disciplinas ministradas na Graduação e na Pós-Graduação vão balizar a vida acadêmica desse trabalhador que, em um esforço supremo, tem procurado se manter ativo.

Nessa "cultura da produtividade" o trabalho do professor entra na exploração capitalista, mas existem outros fatores que caracterizam a precarização do trabalho docente no tocante ao ensino, à pesquisa e à extensão. O número de alunos em sala de aula na graduação é um desses aspectos. Na determinação do Programa de Apoio a Planos de Reestruturação e Expansão das Universidades Federais (REUNI, Dec. 6.096/07), ao qual todas as universidade federais aderiram, a exigência de 18 alunos por professor é um dos fatores que vai contribuir para o fato. A expansão da ordem de $100 \%$ no número de ingressantes, e de $200 \%$ no das matrículas, também como item desse mesmo programa, pode levar a Universidade a uma expansão sem o correspondente aumento do número de vagas para professores, no afã de receber verbas que não ultrapassam $10 \%$ a $20 \%$ do que atualmente é destinado às IFES ${ }^{6}$. Outro aspecto do REUNI é o aumento da taxa média de conclusão que deverá ser elevada, nos próximos 3 anos, para $90 \%$, o que certamente exigirá do professor um trabalho redobrado para alcançar a meta.

A situação de precarização, de intensificação do trabalho docente vem ocasionando sofrimento nos sujeitos envolvidos que se sentem pressionados de forma objetiva e subjetiva para aderirem a esse modelo de Universidade mercantilizada. A pressão ocorre não somente na forma das cobranças de órgãos como a CAPES, mas dos Programas de Pós-Graduação que precisam garantir a nota obtida para manter o número de bolsas para os estudantes e outros recursos.

Um dos sinais da mudança na cultura acadêmica fica bem evidenciado na fala de um dos professores sujeitos da pesquisa referida neste texto e que ingressou em um Programa de Pós-Graduação em 1989:

Antes os orientandos andavam atrás dos professores-orientadores. Agora, com as exigências dos Programas, nós temos que correr atrás deles

6 Os R \$ 2,5 bilhões destinados a financiar os quatro anos de implementação do Programa de Reestruturação e Expansão das Universidades Federais (Reuni) já foram comprometidos nos dois primeiros anos do projeto e não há previsões de como o governo que tomará posse em 2010 arcará com a despesa oriunda desse crescimento desenfreado das universidades públicas, promovido pelo governo Lula. Durante a inauguração do novo prédio do Instituto de Ciências Biológicas da Universidade de Brasília - UnB, em 10 de agosto, [2009] o ministro da Educação, Fernando Haddad, confirmou que os recursos estão esgotados. "Isso significa que o meu sucessor terá que buscar mais alguns bilhões para atender os reitores das universidades federais", disse ele, conforme noticiou a Agência Brasil: <http://www.andes.org.br/imprensa/ultimas/contatoview.asp?key=6015>. 
para que terminem suas dissertações, teses e possamos fechar o Lattes. Ainda não fiz isso, mas tenho ouvido colegas dizerem que sentam com o orientando para juntos escreverem a dissertação. E fazem isso como uma forma de garantir a defesa e o ponto no Lattes.

Contudo, a maior cobrança vem do próprio professor que sente o equilíbrio psíquico comprometido à medida que é visto como um doutor "não produtivo", sentindo-se como um professor de classe inferior. Na "nova" cultura acadêmica há uma cobrança para que todos os doutores se engajem nos Programas de Pós-Graduação. A própria Universidade vem priorizando esses Cursos em detrimento dos Cursos de Graduação.

O individualismo, a competição, marcas do liberalismo, estão muito vivas nessa face perversa que a Universidade pública vem assumindo e o professor, como um dos principais protagonistas da instituição, vem sendo penalizado nesse modelo de uma Universidade que teve sua identidade "alterada", sua cultura acadêmica modificada para se aproximar do mercado, sua autonomia violada e que, para sobreviver, instituiu o capitalismo acadêmico e a cultura da produtividade.

As políticas educacionais têm sido pródigas com relação às reestruturações do trabalho docente e da profissão. Alguns dos aparatos legais aprovados a partir da última década, em todo o mundo, têm trazido a marca da alteração do trabalho do docente e da descaracterização deste enquanto um profissional da educação. Na realidade tem havido um aprofundamento de determinadas práticas concernentes ao professor do $3^{\circ}$ grau, numa lógica que atende as preocupações emanadas por organismos internacionais. O PREAL (2003), por exemplo, deixa claro que um dos grandes obstáculos para a implantação de reformas são os professores, sobretudo por meio dos sindicatos.

O criador do Consenso de Washington coloca que uma das dificuldades à plena implantação e ao sucesso das reformas é o fato de haver por parte do governo confronto político com alguns grupos sociais, dando destaque ao grupo que constitui o poder judiciário e ao grupo dos professores das escolas públicas. Williamson (2004) considera os professores um "dos mais fortes e entrincheirados grupos sociais", o que os torna "obstáculos políticos espinhosos".

Istance (2002), em um documento elaborado para a Organização de Cooperação e Desenvolvimento Econômico (OCDE), descreve alguns cenários para a escola, que poderão ocorrer entre 15 a 20 anos, nos quais o trabalho do professor é apontado em cada uma das situações de forma diferente. Em um dos casos o prognóstico é que a escola não será mais dependente do trabalho docente: a fronteira entre professores e alunos, pais e professores, ensino e 
coletividade tende a desaparecer. Novos profissionais aparecem e eles podem ser contratados para o ensino, ou apenas na qualidade de consultores. O cenário mais preocupante em relação ao futuro do trabalho docente feito pela OCDE é aquele que indica que novos profissionais do ensino tendo perfis diversos público, privado, tempo integral, tempo parcial - serão criados no mercado da educação e novas possibilidade de formação e de certificação serão definidas. Numa lógica de mercado, esses profissionais serão mais facilmente recrutados. Em se cumprindo esses prognósticos a profissão professor tende a desaparecer e o trabalho desse "novo" profissional será distinto daquele hoje executado pelo docente.

Esses aspectos sobre a profissão e o trabalho docente têm influenciado diferentes países que buscam, por meio de reformas, uma adequação do trabalho docente ao novo modelo, nos quais a lógica empresarial, mercantilista vem ganhando força e ocupando um lugar importante nas políticas públicas.

Tomando-se por base essas reformas, a organização do trabalho docente passará por sérias mudanças, podendo vir a alterar o status profissional e as relações de trabalho. Essas políticas públicas vão alterar a divisão das tarefas, a discriminação das atividades, a divisão dos tempos, e, em breve, modificarão a organização do trabalho docente.

Além disso, essas mudanças levarão o docente a uma sobrecarga de trabalho, ultrapassando as horas contratadas, o que, em geral, provoca um desgaste físico e emocional, confirmando o que as pesquisas têm mostrado sobre o abandono e a desistência do professor.

As perspectivas em relação à Universidade pública e ao trabalho docente são de, por meio da organização do movimento docente, haver um processo de resistência às investidas de privatização, precarização, intensificação, flexibilização do trabalho. Essa resistência deve também sinalizar um avanço na defesa dos direitos dos trabalhadores da educação o que implica a luta por melhores condições de trabalho, da carreira e da valorização desse trabalhador.

As tendências, se não houver resistência organizada, do trabalho docente é a de ainda uma maior intensificação, precarização e flexibilização dos direitos trabalhistas como reflexo da privatização da educação superior e da heteronomia existente relativa às instituições públicas.

As propostas de mudança desse quadro podem se resumir na luta pela Universidade pública, gratuita e com qualidade que atenda aos interesses sociais. Dessa forma o trabalho docente terá outra configuração. 


\section{Considerações finais}

Em tempos de globalização e da "sociedade do conhecimento" o trabalho do docente das instituições de educação superior, com destaque para a Universidade, mudou substancialmente. A Universidade que surgiu no século XIII e mesmo a Universidade moderna, surgida no início do século XIX, parece não existir mais, ou pelo menos alterou suas finalidades.

Nesse contexto um dos principais protagonistas dessa instituição de educação, o professor, foi atingido na sua plenitude. A produção de conhecimento se voltou para atender às exigências do mercado, numa heteronomia materializada pela subordinação do público ao privado. $\mathrm{O}$ capitalismo acadêmico passou a ser uma realidade no interior dessas instituições que devem ser autônomas, democráticas e referenciadas pela sociedade. Para tanto houve necessidade de desregulamentar a universidade e estabelecer novas regulações, a partir dessa realidade forjada pela mercantilização e o empresariamento da educação.

Houve assim uma reconfiguração do trabalho docente e ao mesmo tempo um desmantelamento no movimento dos professores, o que vem dificultando a resistência e o avanço da luta no sentido da defesa de uma universidade pública e gratuita e de um trabalho docente que tenha seu valor social reconhecido.

A falta de investimento em educação superior e em ciência e tecnologia, por parte do governo, tornou o professor um empreendedor que precisa buscar recursos para financiar suas pesquisas e para tanto tem que atender aos critérios das agências de fomento que se assentam numa contabilidade acadêmica, ou num quantitativismo absurdo. Essa lógica vem dominando os professores que têm, por uma questão de sobrevivência material e acadêmica, se inserido nessa racionalidade técnica, modificando seus hábitos e rotina.

Essa situação tem estabelecido uma nova forma de convivência entre os professores, criando desconfianças, acirrando competitividades e produzindo, em grande escala, com exceções, produções que são apresentadas em forma de artigos ou comunicações, por vezes pouco lidas. Além desses aspectos outros de maior importância estão acontecendo, como os relativos à saúde do professor, ao lazer, à vida familiar e à saúde mental. $\mathrm{O}$ fato começa a se agravar e a ocupar um lugar na agenda dos estudiosos que têm utilizado os próprios artigos para discutir o assunto.

Contudo, essa não é uma realidade dada, ela foi criada e como tal, num processo dialético, ela pode ser desconstruída e construída ou reconstruída. As funções sociais desse espaço envolvem, nessa caminhada, o movimento docente organizado, sobretudo o sindicato, que tem desempenhado um papel fundamental 
na direção da defesa da educação como um direito humano fundamental, um bem acessível a todos, além do próprio docente, enquanto um sujeito social que pode interferir, dadas as condições objetivas, nos rumos dessa instituição.

A Educação Superior e o Trabalho Docente se constituem em uma história em construção permanente e envolvem todos aqueles que direta ou indiretamente estão implicados no processo de produção e socialização do saber engajado, comprometido com o social, com a construção de outra sociedade.

\section{REFERÊNCIAS}

AGLIETTA, M. Régulation et crises du capitalisme. Paris: Odile Jacob, 1976.

ANDES-SN. Análise do Projeto de Lei 7.200/2006. Disponível em: <http://www.andes. org.br/imprensa/arquivo/default_reforma_universitaria.asp>. Acesso em: jan. 2007.

BANCO MUNDIAL. La enseñanza superior. Las lecciones derivadas de la experiencia, 1994. Disponível em: <http://www1.worldbank.org/education/tertiary/documents/0101344Sp.pdf>. Acesso em: fev. 2002.

BARroso, J. (Org). A Regulação das Políticas Públicas da Educação. Lisboa: Educa, 2006.

BIANCHETTI, L.; MACHADO, A.; M. N. "Reféns da produtividade” sobre produção do conhecimento, saúde dos pesquisadores e intensificação do trabalho na PósGraduação, 2007. Disponível em: <http://www.anped.org.br/reunioes/30ra/trabalhos/ GT09-3503--Int.pdf>. Acesso em: dez. 2007.

BOSI, A. P. A Precarização do Trabalho Docente nas Instituições de Ensino Superior do Brasil nesses últimos 25 anos. Revista Educação \& Sociedade, Campinas, v. 28, n. 101, p. 1503-1523, set./dez. 2007.

BRASIL. Reforma da Educação Superior. Projeto de Lei 7.200 de 2006. Estabelece normas gerais da educação superior, regula a educação superior no sistema federal de ensino, altera as Leis nos 9.394, de 20 de dezembro de 1996; 8.958, de 20 de dezembro de 1994; 9.504, de 30 de setembro de 1997; 9.532, de 10 de dezembro de 1997; 9.870, de 23 de novembro de 1999; e dá outras providências. Disponível em: $<$ http://www. contee.org.br/coordenacao/geral/materia_17.htm>. Acesso em: jan. 2007. 
BRASIL. Decreto no . 6.096, de 24 de abril de 2007. Institui o Programa de Apoio a Planos de Reestruturação e Expansão das Universidades Federais REUNI. D.O.U. de 25 de abril de 2007, p. 7.

DIAS SOBRINHO, J. Dilemas da educação superior no mundo globalizado: sociedade do conhecimento ou economia do conhecimento? São Paulo: Casa do Psicólogo, 2005.

GOERGEN, P. Apresentação. In: DIAS SOBRINHO, J. Dilemas da educação superior no mundo globalizado: sociedade do conhecimento ou economia do conhecimento? São Paulo: Casa do Psicólogo, 2005.

ISTANCE, D. Escolas para o Futuro? OCDE, 2002

LE GRAND, J. Los cuasi mercados y la política social. In: OROVAL, E. (Coord). Economia de la Educación. Espanha: Editores Ariel, 1996.

LEHER, R. A Contra-Reforma Universitária de Lula da Silva. 2006. Disponível em: $<\mathrm{http}$ //www.adunesp.org.br/reformas/universitaria/>. Acesso em: abr. 2007.

MAUÉS, O. As Politicas de Avaliação da Educação Superior, o Trabalho Docente e a Cultura Acadêmica: as possíveis relações. Projeto de Pesquisa financiado pelo CNPq, 2009.

MEC. GABINETE DO MINISTRO. Portaria Normartiva Interministerial $\mathrm{n}^{\circ} 22$, de 30 de abril de 2007. Disponível em: <http://www.adur-rj.org.br/4poli/gruposadur/gtpe/ portaria_normativa22_2_5_2007.htm. Acesso em maio 2007>.

MEC. GABINETE DO MINISTRO. Portaria Normartiva Interministerial $\mathrm{n}^{\circ} 224$, de 24 de julho de 2007. Disponível em: $<$ http://www.adur-rj.org.br/4poli/gruposadur/gtpe/ portaria_normativa22_2_5_2007.htm>. Acesso em: ago. 2007.

MEC. CNE. Documento para o Fórum Nacional de Educação Superior. Disponível em: $<$ http://portal.mec.gov.br/index.php?option=com_content\&view=article\&id=12 478\&Itemid $=769>$.

MOLLIS, M. Un breve diagnóstico de las universidades argentinas: identidades alteradas. In: MOLLIS, M. (Org). Las universidades en América Latina: ¿Reformadas o alteradas? 2003. Disponível em: <http://bibliotecavirtual.clacso.org.ar/ar/libros/mollis/ mollis.html>. Acesso em: jan. 2009.

NAIDORF, J. La privatización el conocimiento público en universidades públicas. 2005. Disponível em: <http://bibliotecavirtual.clacso.org.ar/ar/libros/lbecas/espacio/ Naidorf.pdf>. Acesso em: fev. 2006.

NEAVE, G. Les études supérieures à l'université aujourd'hui. Revue des Sciences de l'Éducation, v. xxix, n. 2, p. 397-414, 2003. 
OCDE. Enseignement supérieur pour la société de la connaissance. Examen thématique de l'OCDE sur l'enseignement supérieur : Rapport de synthèse. 2008. Disponível em: $<$ http://www.oecd.org/dataoecd/20/5/40345193.pdf>. Acesso fev 2009.

PEREIRA, L.C.B. A reforma do Estado dos anos 90: lógica e mecanismos de controle. Lua Nova, São Paulo, n. 45, p. 49-95, 1998.

PREAL. Sindicatos docentes y gobiernos: Conflictos y diálogos en torno a la Reforma Educativa en América Latina. Santiago de Chile: PREAL, 2003. Disponível em: <http:// www.ilo.org/public/spanish/region/ampro/cinterfor/newsroom/resenas/2004/preal. $\mathrm{htm}>$. Acesso em: maio 2004.

SCHUGURENSKY, D. Autonomia, heteronomía, y los dilemas de la educación superior en la transición al siglo 21. 2003. Disponível em: $<$ http://firgoa.usc.es/drupal/ node/9639>. Acesso em: maio 2005.

SLAUGHTER, S.; LESLIE, L. L. Academic capitalism: politics, policies and the entrepreneurial university. Baltimore, Maryland:The Johns Hopkins University Press, 1997.

UNESCO. IELSAC. Declaração da Conferência Regional de Educação Superior na América Latina e no Caribe. 2008. Disponível em: <http://www.cres2008.org/pt/index. php>. Acesso em: jan. 2009.

UNESCO. Conférence mondiale sur l'enseignement supérieur 2009 : La nouvelle dynamique de l'enseignement supérieur et de la recherche au service du progrès social et du développement. Disponível em: $<$ http://www.unesco.org/fileadmin/MULTIMEDIA/ HQ/ED/ED/pdf/WCHE_2009/Communique\%20final\%20FR\%20160709.pdf > . Acesso em: ago. 2009.

WILLIAMSON, J. Uma agenda de trabalho para retomar o crescimento e as reformas. In: KUCZYNSKI, P. P.; WILLIAMSON, J. Depois do Consenso de Washington. Retomando o crescimento e a reforma na América Latina. São Paulo: Saraiva, 2004.

Texto recebido em novembro de 2009.

Texto aprovado em maio de 2010. 